\title{
Short communication: $\beta$-Lactam resistance and vancomycin heteroresistance in Staphylococcus spp. isolated from bovine subclinical mastitis
}

\author{
Priscila Luiza Mello, ${ }^{* 1}$ Luiza Pinheiro, ${ }^{*} \dagger$ Lisiane de Almeida Martins, $\ddagger$ \\ Maria Aparecida Vasconcelos Paiva Brito, $§$ and Maria de Lourdes Ribeiro de Souza da Cunha* \\ *Department of Microbiology and Immunology, Institute of Biosciences of Botucatu, Universidade Estadual Paulista (UNESP), \\ Botucatu 18618-970, Brazil \\ †Department of Anatomic Pathology, Instituto Lauro de Souza Lima, Bauru, 17034-971, Brazil \\ łUniversidade Paranaense (UNIPAR), Umuarama 87502-210, Brazil \\ $\S$ Embrapa Dairy Cattle, Juiz de Fora 36038-330, Brazil
}

\begin{abstract}
The use of antimicrobial agents has led to the emergence of resistant bacterial strains over a relatively short period. Furthermore, Staphylococcus spp. can produce $\beta$-lactamase, which explains the survival of these strains in a focus of infection despite the use of a $\beta$-lactam antibiotic. The aim of this study was to evaluate the resistance of Staphylococcus spp. isolated from bovine subclinical mastitis to oxacillin and vancomycin (by minimum inhibitory concentration) and to detect vancomycin heteroresistance by a screening method. We also evaluated $\beta$-lactamase production and resistance due to hyperproduction of this enzyme and investigated the mecA and mecC genes and performed staphylococcal cassette chromosome mec typing. For this purpose, 181 Staphylococcus spp. isolated from mastitis subclinical bovine were analyzed. Using the phenotypic method, $33(18.2 \%)$ of Staphylococcus spp. were resistant to oxacillin. In contrast, all isolates were susceptible to vancomycin, and heteroresistance was detected by the screening method in 13 isolates. Production of $\beta$-lactamase was observed in 174 (96\%) of the Staphylococcus spp. isolates. The mecA gene was detected in 8 isolates, all of them belonging to the species Staphylococcus epidermidis, and staphylococcal cassette chromosome mec typing revealed the presence of type I and type IV isolates.
\end{abstract}

Key words: $\beta$-lactam, resistance, mecC and mecA, staphylococci, cattle

\section{Short Communication}

As one of Brazil's most important agricultural products, milk and milk products play a relevant economic

Received November 21, 2016.

Accepted April 11, 2017.

${ }^{1}$ Corresponding author: priscila_mello@msn.com and social role, generating income and employment for the population (Carvalho et al., 2003). The indiscriminant use of antibiotics, including vancomycin, one of the last therapeutic options for staphylococcal infections, has selected for strains with reduced susceptibility to this drug (Schwalbe et al., 1987). According to Natoli et al. (2009), the heteroresistant phenotype of these strains may be associated with treatment failure or may be a precursor of glycopeptide resistance.

The objective of the present study was to evaluate resistance of Staphylococcus spp. isolated from bovine subclinical mastitis to oxacillin and vancomycin by a phenotypic method (MIC) and to detect vancomycin resistance by a screening method. Additionally, Staphylococcus spp. isolates were submitted to determination of $\beta$-lactamase production and hyperproduction and investigation of the oxacillin resistance mecA and mec $C$ genes. Staphylococcal cassette chromosome mec $(S C C m e c)$ typing was performed on isolates carrying the resistance gene.

A total of 181 Staphylococcus spp. strains isolated from bovine subclinical mastitis cases in 6 Brazilian states, maintained in the collection of Embrapa Dairy Cattle (Juiz de Fora, Brazil), were studied. Bacterial isolation and identification were performed according to the National Mastitis Council (NMC, 2004) using coagulase and sugar (trehalose, maltose, and mannitol) fermentation tests. Strains belonging to the CNS group were submitted to biochemical tests as proposed by Cunha et al. (2004) for phenotypic identification of the species. Total DNA was extracted using the Illustra kit (GE Healthcare, Little Chalfont, UK). Genotypic identification of CNS was performed using primers targeting conserved sequences adjacent to the $16 \mathrm{~S}$ and $23 \mathrm{~S}$ genes by the internal transcribed spacer-polymerase chain reaction (ITS-PCR) described by Couto et al. (2001), using primers G1 and L1. Polymerase chain reaction using the Staur-4 and Staur-6 primers developed by Straub et al. (1999) was used for S. aureus. Amplifica- 
tion efficiency was monitored by $2 \%$ agarose gel electrophoresis stained with Saber Safe DNA Gel Strain (São Paulo, Brazil) and viewed under a UV transilluminator.

The in vitro susceptibility of the isolates to oxacillin and vancomycin was tested by determining the MIC of these drugs using E-test (AB Biodisk, Solna, Sweden) as follows: Mueller-Hinton culture medium, inoculum size matching the turbidity of a 0.5 McFarland standard, incubation at $35^{\circ} \mathrm{C}$, and MIC determination as the value corresponding to the intersection of the ellipse of bacterial growth inhibition. The interpretation followed the breakpoints proposed by CLSI (2015), which suggests oxacillin breakpoints for $S$. aureus as follows: susceptibility $\leq 2 \mu \mathrm{g} / \mathrm{mL}$; resistance $\geq 4 \mu \mathrm{g} / \mathrm{mL}$; and for CNS: susceptibility $\leq 0.25 \mu \mathrm{g} / \mathrm{mL}$; resistance $\geq 0.5 \mu \mathrm{g} /$ $\mathrm{mL}$. The vancomycin breakpoints for Staphylococcus spp. were susceptibility $<4 \mu \mathrm{g} / \mathrm{mL}$; resistance $\geq 4 \mu \mathrm{g} /$ $\mathrm{mL}$.

The PCR for the detection of mecA was performed using primers mecA1 (AAAATCGATGGTAAAGGTTGG) and mecA2 (AGTTCTGCAGTACCGGATTTG) according to the parameters described by Murakami et al. (1991). International reference strains were included in all reactions: positive control (Staphylococcus aureus ATCC 33591) and negative control (Staphylococcus aureus ATCC 25923). The presence of the $m e c C$ gene was investigated in isolates in which the mecA gene was not detected. The primers and parameters described by García-Álvarez et al. (2011) were used. Typing of SCCmec was performed using the method of Machado et al. (2007), which characterizes types I, II, III, and IV isolates, considering the corresponding molecular weights. As a control for the SCCmec typing, COL strains for SCCmec type I were used; N315 for SCCmec type IA; PER34 for SCCmec type II; AN546 for SCCmec type III; HU25 for SCCmec type IIIA and MW2 for SCCmec type IV. The reaction parameters were $92^{\circ} \mathrm{C}$ for 3 min followed by 30 cycles of $92^{\circ} \mathrm{C}$ for $1 \mathrm{~min}, 56^{\circ} \mathrm{C}$ for $1 \mathrm{~min}$, and $72^{\circ} \mathrm{C}$ for $1 \mathrm{~min}$ and $30 \mathrm{~s}$.

Production of $\beta$-lactamase was detected using nitrocefin-impregnated disks placed on Staphylococcus spp. colonies previously incubated at $35^{\circ} \mathrm{C}$ for $24 \mathrm{~h}$ on a Mueller-Hinton agar plate with the E-test oxacillin strip. The positive reaction was evidenced by the development of a red color and the negative color change. International reference strains were used as positive (Staphylococcus aureus ATCC 33591) and negative (Staphylococcus xylosus ATCC 29979) controls.

Isolates that tested negative for the mecA gene and exhibited oxacillin resistance by the phenotypic method were analyzed to determine whether they were hyperproducers of $\beta$-lactamase using a disk containing amoxicillin $(20 \mu \mathrm{g})$ and clavulanic acid $(10 \mu \mathrm{g})$.
The susceptibility breakpoint was the formation of an inhibition halo of $20 \mathrm{~mm}$ after incubation for $24 \mathrm{~h}$ at $35^{\circ} \mathrm{C}$ (Ghoshal et al., 2004). The screening medium was prepared with brain heart infusion agar (BHI) containing $4 \mu \mathrm{g} / \mathrm{mL}$ (Hiramatsu, 2001) or $6 \mu \mathrm{g} / \mathrm{mL}$ vancomycin (CLSI 2015). Staphylococcus aureus (ATCC 29213) susceptible to vancomycin and vancomycin-resistant Enterococcus faecalis (ATCC 51299) were used as negative and positive control, respectively.

Among the 181 isolates studied, $82(45.3 \%)$ were identified as S. aureus and $99(54.7 \%)$ were classified as CNS: $27(14.9 \%)$ Staphylococcus chromogenes, 26 (14.4\%) Staphylococcus epidermidis, 17 (9.4\%) Staphylococcus saprophyticus, 6 (3.3\%) Staphylococcus warneri, 6 (3.3\%) Staphylococcus simulans, 6 (3.3\%) Staphylococcus haemolyticus, 2 (1.1\%) Staphylococcus xylosus, 4 (2.2\%) Staphylococcus hominis, and 5 (2.8\%) Staphylococcus hyicus.

Interpretation of the results according to the breakpoints defined by the CLSI (2015) revealed a rate of $33(18.2 \%)$ of Staphylococcus spp. resistant to oxacillin (Table 1). The $\mathrm{MIC}_{50}$ (concentration that inhibits $50 \%$ of isolates tested) was $0.25 \mu \mathrm{g} / \mathrm{mL}$ and the $\mathrm{MIC}_{90}$ (concentration that inhibits $90 \%$ of isolates tested) was 1.5 $\mu \mathrm{g} / \mathrm{mL}$ (Table 2). In contrast, for vancomycin, S. aureus exhibited $\mathrm{MIC}_{50}$ and $\mathrm{MIC}_{90}$ values of 0.5 and $1.5 \mu \mathrm{g} /$ $\mathrm{mL}$, respectively. In CNS, the $\mathrm{MIC}_{50}$ and $\mathrm{MIC}_{90}$ values were 1.0 and $1.5 \mu \mathrm{g} / \mathrm{mL}$, respectively. All Staphylococcus spp. analyzed were susceptible to vancomycin.

The mecA gene was detected in $8(4.4 \%)$ CNS isolates; 2 did not exhibit phenotypic resistance (Table 3). All isolates carrying the $m e c A$ gene belonged to the species S. epidermidis and originated from Paraná, Santa Catarina, or Minas Gerais. The $m e c A$ gene was not detected in the remaining isolates, although 27 (14.9\%) strains were resistant by the phenotypic method. Thus, the presence of the mecA homolog mecC was investigated. A PCR product with a size similar to that expected for this gene was detected in 12 of these 27 isolates. To confirm the presence of $m e c C$, the 12 isolates were sent for sequencing. Sequence analysis showed that the products were not mecC but a gene with $99 \%$ identity to $m e c A$, which was considered an ancestor of the gene (GenBank accession number: AB547234.1). Five $(62.5 \%)$ of the 8 isolates analyzed were classified as SCCmec type I. The other $3(37.5 \%)$ isolates were classified as type IV.

Regarding $\beta$-lactamase production, 174 (96.13\%) of the 181 isolates tested were positive. Among the negative isolates, only $2(2.5 \%)$ were $S$. aureus, whereas the other $5(4.85 \%)$ were identified as CNS. Hyperproduction of $\beta$-lactamase was evaluated in isolates that were resistant to oxacillin by the phenotypic method but that tested negative for detection of the mecA and mecC 
Table 1. Phenotypic resistance (number of isolates) to oxacillin and vancomycin, vancomycin heteroresistance, and hyperproduction of $\beta$-lactamase in Staphylococcus spp. isolated from bovine subclinical mastitis

\begin{tabular}{lcccc}
\hline Species & $\begin{array}{c}\text { Resistance to } \\
\text { oxacillin }\end{array}$ & $\begin{array}{c}\text { Resistance to } \\
\text { vancomycin }\end{array}$ & $\begin{array}{c}\text { Vancomycin } \\
\text { heteroresistance }\end{array}$ & $\begin{array}{c}\beta \text {-lactamase } \\
\text { hyperproduction }\end{array}$ \\
\hline S. aureus & 1 & 0 & 1 & 2 \\
S. chromogenes & 5 & 0 & 0 & 4 \\
S. epidermidis & 9 & 0 & 5 & 3 \\
S. haemolyticus & 1 & 0 & 4 & 9 \\
S. saprophyticus & 10 & 0 & 2 & 3 \\
S. simulans & 3 & 0 & 0 & 2 \\
S. xylosus & 2 & 0 & 1 & 26 \\
S. warneri & 2 & 0 & 13 & 26 \\
Total & 33 & & &
\end{tabular}

genes. $\beta$-Lactamase hyperproduction was detected in 26 (96.3\%) of the 27 isolates tested. The species with the largest number of hyperproducers was $S$. saprophyticus, with $9(33.3 \%)$ isolates (Table 1$)$.

Thirteen $(7.18 \%)$ of the 181 isolates grew on BHI agar plates containing 4 or $6 \mu \mathrm{g} / \mathrm{mL}$ vancomycin. Seven isolates that grew at the lower concentration also exhibited growth when the concentration was increased to $6 \mu \mathrm{g} / \mathrm{mL}$ (Table 1). The following species exhibited heteroresistance: $S$. epidermidis $(\mathrm{n}=5)$, S. haemolyticus $(\mathrm{n}=4)$, S. saprophyticus $(\mathrm{n}=2)$, S. warneri $(\mathrm{n}=$ $1)$, and $S$. aureus $(\mathrm{n}=1)$.

Thirty-three $(18.2 \%)$ isolates were resistant to oxacillin by the phenotypic method, but only 8 (4.4\%) of these isolates carried the mecA gene. The remaining isolates may have developed resistance through other mechanisms, such as hyperproduction of $\beta$-lactamase (Geha et al., 1994). This result demonstrates the need to use phenotypic and genotypic methods to detect resistance. Investigation of SCCmec types in the mecApositive isolates revealed the presence of cassette type I in 5 isolates, whereas 3 isolates carried type IV. Both cassette types (I and IV) carry the mecA gene as the single resistance determinant, conferring resistance only to this class of antimicrobials (Boyle-Vavra and Daum, 2007).

Staphylococcal cassette chromosome mec typing is an important tool for the understanding of the epidemiology and clonal relationship of methicillin-resistant
Staphylococcus aureus (MRSA), which can be classified into hospital-associated (HA)-MRSA, communityacquired (CA)-MRSA, and livestock-associated (LA)MRSA. Substantial differences exist between these types in terms of the distribution of toxins, risk factors, and antimicrobial susceptibility (Vandenesch et al., 2003). The SCCmec types IV, V, and VII are frequently associated with CA-MRSA, which carry a smaller cassette that confers resistance only to $\beta$-lactam antimicrobials. In contrast, HA-MRSA frequently harbor type I, II, or III and are usually resistant to multiple drugs (Vandenesch et al., 2003), and LA-MRSA frequently harbor SCCmec type XI and are found in a variety of Staphylococcus spp. isolated from different animal species (Stefani et al., 2012).

The presence of the mecA gene in 2 isolates that were susceptible to oxacillin by the phenotypic method, both carrying SCCmec type IV, suggests the lack of phenotypic expression of oxacillin resistance or the presence of heterogeneous resistance. The same was reported in a study conducted in China (Pu et al., 2014) in which 49 isolates carried mecA and 37 were susceptible to oxacillin by phenotypic methods. Taken together, these results suggest the need for genotypic methods to accurately identify oxacillin resistance.

A total of $33(18.2 \%)$ Staphylococcus spp. were resistant to oxacillin. Variation in the susceptibility profile of mastitis isolates has been observed between different geographic regions and even between herds of the same

Table 2. Interpretative breakpoints of MIC of staphylococci strains isolated from bovine subclinical mastitis

\begin{tabular}{lccccccc}
\hline & \multicolumn{3}{c}{ Oxacillin $^{1}$} & & \multicolumn{3}{c}{ Vancomycin $^{2}$} \\
\cline { 2 - 3 } Species & $\begin{array}{c}\mathrm{MIC}_{50} \\
(\mu \mathrm{g} / \mathrm{mL})\end{array}$ & $\begin{array}{c}\mathrm{MIC}_{90} \\
(\mu \mathrm{g} / \mathrm{mL})\end{array}$ & $\begin{array}{c}\text { Resistant } \\
(\text { no. })\end{array}$ & & $\begin{array}{c}\mathrm{MIC}_{50} \\
(\mu \mathrm{g} / \mathrm{mL})\end{array}$ & $\begin{array}{c}\mathrm{MIC}_{90} \\
(\mu \mathrm{g} / \mathrm{mL})\end{array}$ & $\begin{array}{c}\text { Resistant } \\
(\text { no. })\end{array}$ \\
\hline Staphylococcus aureus & 0.094 & 0.25 & 1 & & 0.50 & 1.0 & 0 \\
CNS & 0.25 & 1.5 & 32 & & 1.0 & 1.5 & 0 \\
\hline${ }^{1}$ Oxacillin breakpoints: $S$. aureus: susceptibility $\leq 2 \mu \mathrm{g} / \mathrm{mL} ;$ resistance $\geq 4 \mu \mathrm{g} / \mathrm{mL} ;$ CNS: susceptibility $\leq 0.25$ \\
$\mu \mathrm{g} / \mathrm{mL}$; resistance $\geq 0.5 \mu \mathrm{g} / \mathrm{mL}$ (CLSI, 2015).
\end{tabular}


Table 3. Comparison of the presence of the mecA gene by PCR with the phenotypic method

\begin{tabular}{|c|c|c|c|c|}
\hline \multirow[b]{3}{*}{ PCR } & \multicolumn{4}{|c|}{ Phenotypic method: Oxacillin $(1 \mu \mathrm{g} / \mathrm{mL})$} \\
\hline & \multicolumn{2}{|c|}{ Susceptible } & \multicolumn{2}{|c|}{ Resistant } \\
\hline & No. & $\%$ & No. & $\%$ \\
\hline$\overline{m e c A+}$ & 2 & 1.1 & 6 & 3.3 \\
\hline mecA - & 146 & 80.6 & 27 & 14.9 \\
\hline Total & 148 & 81.7 & 33 & 18.2 \\
\hline
\end{tabular}

region (Owens et al., 1988). The present study instead showed that, despite the widespread use of antimicrobial agents for mastitis treatment, most isolates were susceptible to the antimicrobials tested. Additionally, the MIC of oxacillin and vancomycin were lower for $S$. aureus than for CNS.

Regarding the screening method for detecting vancomycin-heteroresistant Staphylococcus spp., our results showed that $7.1 \%$ of the isolates were positive in medium containing 4 or $6 \mu \mathrm{g} / \mathrm{mL}$ of the antibiotic. Of these positive isolates, $92.3 \%$ belonged to the group of CNS. Hiramatsu (2001) suggested that, if growth is observed on BHI agar containing $4 \mu \mathrm{g} / \mathrm{mL}$ vancomycin, the strain can already be considered heteroresistant to vancomycin. According to Natoli et al. (2009), the heteroresistance phenotype of these isolates may be associated with treatment failure or may be a precursor of glycopeptide resistance. A study carried out in Turkey analyzed 100 strains of staphylococci from cases of bovine mastitis; 10 strains were found to have reduced susceptibility to vancomycin with a MIC of 4 to $8 \mu \mathrm{g} / \mathrm{mL}$. A PCR was performed for the detection of the vanA gene and the results showed that the strains did not carry this gene. Because the vanA gene was not present, the mechanism for heteroresistant strains could be explained by changes in the cell wall biosynthesis of the strains (Pehlivanoglu and Yardimci, 2012). The clinical significance of heteroresistance is not fully understood, and a limiting factor in our understanding is the small number of studies involving bovine mastitis isolates.

Regarding vancomycin heteroresistance, the association of these results with those of phenotypic resistance to oxacillin and presence of the mecA gene showed that only isolates carrying SCCmec type I exhibited heteroresistance. Although the mechanism of vancomycin resistance has not been studied in these heteroresistant subpopulations, with the confirmation of the presence or absence of the van genes, this resistance is probably due to thickening of the bacterial cell wall, preventing entry of the antibiotic into the cell (Billot-Klein et al., 1996).
In the present study, $174(96.13 \%)$ of the isolates produced $\beta$-lactamase. In addition, $26(96.3 \%)$ of the 27 oxacillin-resistant isolates that did not carry the mecA or mecC gene were confirmed to be hyperproducers of $\beta$-lactamase. These findings indicate that the presence of these $\beta$-lactamase producers may favor the survival of other antibiotic-susceptible microorganisms in an infectious process (Tavares, 2001).

The present results demonstrate the need to evaluate the microbiological and molecular aspects of bovine mastitis isolates because the presence of the mecA gene in $S$. epidermidis confirms that cow milk can harbor resistant strains, even though these strains may have come from humans.

\section{ACKNOWLEDGMENTS}

Financial support for this study was provided by Fundação de Amparo à Pesquisa do Estado de São Paulo (FAPESP, São Paulo, Brazil; grants 2012/241350 and 2015/01401-4) and CNPq (grant 578430/2008-8, Brazil).

\section{REFERENCES}

Billot-Klein, D., L. Gutmann, D. Bryant, D. Bell, J. Van Heijenoort J. Grewal, and D. M. Shlaes. 1996. Peptidoglycan synthesis and structure in Staphylococcus haemolyticus expressing increasing levels of resistance to glycopeptide antibiotics. J. Bacteriol. 178:46964703.

Boyle-Vavra, S., and R. S. Daum. 2007. Community-acquired methicillin-resistant Staphylococcus aureus: The role of Panton-Valentine leukocidin. Lab. Invest. 87:3-9.

Carvalho, L. A., L. P. Novaes, A. T. Gomes, J. E. C. Miranda, and A. C. C. L. Ribeiro. 2003. Sistema de produção de leite (zona da mata). Sistema de Produção, 1. Embrapa Gado de Leite. https:// sistemasdeproducao.cnptia.embrapa.br/FontesHTML/Leite/ LeiteZonadaMataAtlantica/.

CLSI (Clinical and Laboratory Standards Institute). 2015. Performance Standards for Antimicrobial Disk Susceptibility Tests; Approved Standard-Eleventh Edition (M02-A10). CLSI, Wayne, PA.

Couto, I., S. Pereira, M. Miragaia, I. S. Sanches, and H. Lencastre. 2001. Identification of clinical staphylococcal isolates from humans by internal transcribed spacer PCR. J. Clin. Microbiol. 39:3099 3103.

Cunha, M. L. R. S., Y. K. Sinzato, and L. V. A. Silveira. 2004. Comparision of methods for identification of coagulase-negative staphylococci. Mem. Inst. Oswaldo Cruz 99:855-860.

García-Álvarez, L., M. T. Holden, H. Lindsay, C. R. Webb, D. F. Brown, M. D. Curran, E. Walpole, K. Brooks, D. J. Pickard, C. Teale, J. Parkhill, S. D. Bentley, G. F. Edwards, E. K. Girvan, A. M. Kearns, B. Pichon, R. L. Hill, A. R. Larsen, R. L. Skov, S. J. Peacock, D. J. Maskell, and M. A. Holmes. 2011. Methicillinresistant Staphylococcus aureus with a novel mecA homologue in human and bovine populations in the UK and Denmark: A descriptive study. Lancet Infect. Dis. 11:595-603.

Geha, D. J., J. R. Uhl, C. A. Gustaferro, and D. H. Persing. 1994 Multiplex PCR for identification of methicillin-resistant staphylococci in the clinical laboratory. J. Clin. Microbiol. 32:1768-1772.

Ghoshal, U., K. N. Prasad, M. Singh, D. P. Tiwari, and A. Ayyagari. 2004. A comparative evaluation of phenotypic and molecular methods for the detection of oxacillin resistance in coagulase-negative staphylococci. J. Infect. Chemother. 10:86-89. 
Hiramatsu, K. 2001. Vancomycin-resistant Staphylococcus aureus: A new model of antibiotic resistance. Lancet Infect. Dis. 1:147-155.

Machado, A. B. M. P., K. C. Reiter, R. M. Paiva, and A. L. Barth. 2007. Distribution of staphylococcal cassette chromosome mec (SCCmec) types I, II, III and IV in coagulase-negative staphylococci from patients attending a tertiary hospital in southern Brazil. J. Med. Microbiol. 56:1328-1333.

Murakami, K., K. Minamide, K. Wada, E. Nakamura, H. Teraoka, and S. Watanabe. 1991. Identification of methicillin-resistant strains of staphylococci by polymerase chain reaction. J. Clin. Microbiol. 29:2240-2244.

Natoli, S., C. Fontana, M. Favaro, A. Bergamini, G. P. Testore, S. Minelli, M. C. Bossa, M. Casapulla, G. Broglio, A. Beltrame, L. Cudillo, R. Cerretti, and F. Leonardis. 2009. Characterization of coagulase-negative staphylococcal isolates from blood with reduced susceptibility to glycopeptides and therapeutic options. BMC Infect. Dis. 9:83.

NMC (National Mastitis Council). 2004. Microbiological Procedures for the Diagnosis of Bovine Udder Infection and Determination of Milk Quality. 4th ed. National Mastitis Council, Verona, WI.

Owens, W. E., J. L. Watts, R. L. Boddie, and S. C. Nickerson. 1988. Antibiotic treatment of mastitis: comparison of intramammary and intramammary plus intramuscular therapies. J. Dairy Sci. 71:3143-3147.

Pehlivanoglu, F., and H. Yardimci. 2012. Detection of methicillin and vancomycin resistance in Staphylococcus strains isolated from bo- vine milk samples with mastitis. Kafkas Univ. Vet. Fak. 18:849855

Pu, W., Y. Su, J. Li, C. Li, and Z. Yang. 2014. High incidence of oxacillin-susceptible mecA-Positive Staphylococcus aureus (OSMRSA) associated with bovine mastitis in China. PLoS One 9:e88134 https://doi.org/10.1371/journal.pone.0088134.

Schwalbe, R. S., J. T. Stapleton, and P. H. Gilligan. 1987. Emergence of vancomycin resistance in coagulase-negative staphylococci. N Engl. J. Med. 316:927-931.

Stefani, S. D. R., J. A. Chung, A. W. Lindsay, A. M. Friedrich, H. Kearns, and F. M. Westh MacKenzie. 2012. Staphylococcus aureus resistente à meticilina (MRSA): epidemiologia global e harmonização dos métodos de tipagem. Int. J. Antimicrob. Agents $39: 273-282$.

Straub, J. A., L. C. Herte, and W. P. Hammes. 1999. A $23 \mathrm{~S}$ rDNAtargeted polymerase chain reaction-based system for detection of Staphylococcus aureus in meat starter cultures and dairy products. J. Food Prot. 62:1150-1156.

Tavares, W. 2001. Resistência bacteriana. Pages 37-62 in Manual de Antibióticos e Quimioterápicos Antiifecciosos. 3rd ed. Atheneu, São Paulo, Brazil

Vandenesch. F., T. Naimi, M. C. Enright, G. Lina, G. R. Nimmo, H. Heffernan, N. Liassine, M. Bes, T. Greenland, M. E. Reverdy, and J. Etienne. 2003. Community-acquired methicillin-resistant Staphylococcus aureus carrying Panton-Valentine leukocidin genes: Worldwide emergence. Emerg. Infect. Dis. 9:978-984. 